\title{
Footwear in children
}

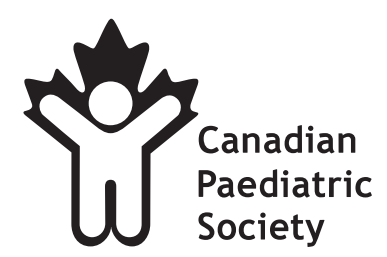

Français en page 122
When should my child start to wear shoes?

Some people think that shoes are needed to support a child's developing leg and foot muscles and bone structure to help prevent future problems with walking. Your child's feet will develop well on their own and don't require any special footwear.

If your child isn't walking yet, she doesn't need to wear shoes. If she has just started walking, shoes will help to prevent accidental injuries. Shoes with higher ankle support don't necessarily offer better support than those with low-cut ankles. However, a shoe with a higher ankle might help at this stage simply because they are harder for your toddler to take off.

Your child's feet will change quickly as he grows. Before 18 months of age, his feet will probably grow by more than one-half a shoe size every 2 months.

Toddler's feet grow an average of one-half a size every three months. Once your child is 3 years of age, his feet will grow by one size every year.

How do I choose the right kind of shoes for my child? Shoes have become softer, wider, lighter and more comfortable. Your child's shoes should:

- Protect his feet;

- Offer some grip on smooth surfaces; and

- Ensure comfortable walking on different types of surfaces (eg, pavement, gravel and sand).

When choosing shoes for your child, check that they:

- Fit snugly at the heel to stop the foot from moving forward while walking;

- Allow room for the toes, approximately $1.25 \mathrm{~cm}$ (a thumb width) between the longest toe and the tip of the shoe while your child is standing up;
- Have a $5 \mathrm{~mm}$ space between the edge of the shoe and all the toes; and

- Have a small crease in the material if you pinch the shoe while your child standing.

Your child should always try on shoes before you buy them.

\section{Corrective footwear}

Corrective footwear are shoes used to fix problems such as flatfoot or intoeing. Most children do not need special footwear. Your child's feet and legs will change naturally as she grows.

\section{What is flatfoot?}

The arch of the foot between the heel and the big toe (the natural curve of the bottom of the foot) develops before 6 years of age. Almost all children younger than 18 months of age have flat feet. This can also be common until your child is 6 years of age. A small number of children still have flatfoot by the time they are 10 years of age.

If your child continues to have flatfoot but it doesn't cause any pain or discomfort, it isn't necessary to use corrective shoes. If your child complains of pain while walking, contact your doctor to discuss your choices.

\section{What is intoeing?}

Intoeing happens when the feet turn inward instead of pointing straight ahead when walking or running. It is common in children and usually gets better as your child gets older, without the use of corrective shoes.

\section{For more information}

- Footwear in children, a practice point by the Canadian Paediatric Society, is available at $<$ www.cps.ca/english/publications/ CommunityPaediatrics.htm>.

This information should not be used as a substitute for the medical care and advice of your physician.

All Canadian Paediatric Society documents are reviewed, revised or retired as needed on a regular basis.

Please consult the Caring for Kids website (www.caringforkids.cps.ca) for the current version.

May be reproduced without permission and shared with patients and their families.

Correspondence: Canadian Paediatric Society, 2305 St Laurent Boulevard, Ottawa, Ontario K1G 4J8. Telephone 613-526-9397,

fax 613-526-3332, Web sites www.cps.ca, www.caringforkids.cps.ca 